\title{
The Measurement of Perceived Intraorganizational Power: A Multi-Respondent Perspective
}

\author{
Cathy A. Enz \\ Indiana University
}

\begin{abstract}
This study found substantial divergence between a general measure of perceived departmental power and an issue-specific measure, and indicates a conceptual distinctiveness between these two common perceptual measures. Using the assessments of three different respondent groups allowed for the cross-validation of the power measures while highlighting differences in perceptions based on group membership. The findings of this study raise the possibility that different dimensions of power (enacted versus potential power) are not equally reflected in the two perceptual measures when departmental members and top managers are the groups assessing each sub-unit's power. Measurement distinctiveness was not found to exist when other departments' members evaluated each subunit's power. This investigation suggests that future studies of power would benefit from utilizing more than one perceptual measure and more than one group of respondents.
\end{abstract}

\section{Introduction}

Most of the research on departmental power reports findings based on a single perceptual measure. The cry for multiple measures has been met by many researchers who have developed both objective and perceptual measures (Pfeffer and Salancik 1974; Hinings, Hickson, Pennings, and Schneck 1974; Provan, Beyer, and Kruytbosch 1980; Beyer 1982), but the importance of developing multiple perceptual measures has remained unexplored. While many researchers have argued that perceptual and objective measures capture different things (Pennings 1973; Sathe 1978), they tacitly assume that perceptual measures capture the same aspects of a construct. Previous attempts to categorize power measures have focussed on demonstrating the divergence or convergence between objective and perceptual measures (Provan et al. 1980; Hinings. Hickson, Pennings, and Schneck 1974; Pfeffer and Salancik 1974; Beyer 1982). While examinations of the difference between perceptual and objective measures are commendable, a closer investigation of perceptual measures is necessary to further clarify the conceptual and methodological properties of power.

It is the purpose of this paper to examine two of the most frequently used measures of perceived departmental power to ascertain whether they represent the same conceptualization of power. Since the findings of research on power are argued to be dependent on the type of measure used (Provan 1980), perceptual measures may reflect different aspects of the concept, thus hampering meaningful interpretation and comparison across studies. Rather than select only one perceptual 
measure and assume other perceptual measures capture the same component of power, the present study will explore two measures for possible distinctiveness.

Three different respondent groups are used to facilitate cross-validation of the two measures. It is expected that if the perceptual measures are reflecting different aspects of power, then the respondent groups should discriminate between the measures. However, it is also possible that respondent groups interpret departmental power from different organizational vantage points, thereby assessing power differently. Thus an additional impediment to interpreting findings based on perceptual measures exists when studies restrict their investigations to one respondent group.

\section{Conceptualizations of Power}

One of the few attempts to explore the comparability of power measures distinguishes between measures which capture power in use as demonstrated in past actions or enacted power, and those that capture power as a capacity or potential to influence (Provan 1980; Provan et al. 1980). This conceptualization carefully categorizes objective measures as tapping either potential or enacted power, but suggests that we do not have a clear understanding of these distinctions in our perceptual measures. According to this analysis, it is likely that perceptual measures reflect both potential and enacted components; thus perceptual measures should be cautiously interpreted since we probably do not know what we are measuring.

While it is agreed that an interpretation of findings based on perceptual measures can be problematic and will be improved by obtaining objective measures, it is also likely that a careful exploration into the convergent and divergent validity of perceptual measures may offer some insight into whether some measures are assessing enacted power while others more directly measure potential power.

Measuring respondents' perceptions of a department's overall or general influence and measuring their perceptions of a sub-unit's ability to affect a variety of critical issues are the two approaches which dominate the limited macro-level power literature. Depending on the researcher, one or the other of these perceptual measures is selected. Although a few researchers use the perceptual measure in combination with objective measures (Hinings et al. 1974; Salancik and Pfeffer 1974), usually only one perceptual measure is selected. The exclusive use of either a general or issue-based perceptual measure in the few existing studies of intraorganizational power may lead to different findings if these two approaches reflect differing degrees of enacted and potential power.

\section{General and Issue-Based Measures}

General measures of perceived power are usually broad-based questions which ask for an overall impression of a subunit's influence. This measure of power 
asks respondents to assess how much influence a specific sub-unit has. Provan (1980) suggests that this approach to measuring perceived power tends to be based on impressions from past observations. Emphasis is placed on what is or has been, and thus reflects the sub-unit's current level of exercised power, referred to as actual, manifest or enacted power, depending on the theorist (Wrong 1979; Provan 1980).

Salancik and Pfeffer (1974) studied departmental power and resource allocation using a general measure of perceived power. These researchers asked department heads to rate the degree of power each sub-unit possessed on a 7-point scale ranging from a great deal of power to very little power. Perrow (1970) asked department members to rate each department's power using a general measure. While a general measure of perceived power was utilized in both of these studies, the perceiving group was different. In the case of Salancik and Pfeffer, the perceiving group was department heads, while Perrow's study utilized departmental employees.

Issue-specific measures use a multi-issue approach to capture the capacity or ability of a given sub-unit to exercise power in various situations or contexts. This conceptualization of power suggests that a sub-unit may have the capacity to influence a variety of different issues, whether or not it uses the power. Potential or latent power is often characterized as something 'to be "possessed" without being "exercised"' (Wrong 1979: 7), and may be reflected in these issue-oriented measures.

In the work of Hinings et al. (1974), a list of seventeen problem areas was used to measure department heads' perceptions of power. A mean score was developed for each department by aggregating the department heads' responses to the multiple issues. A recent study by Hackman (1985) measured comparative subunit power using fourteen issue categories. Both of these studies relied on department heads to report perceptions of power.

One of the few studies to devise two perceptual measures of power at the macro-level reported an insignificant correlation $(r=-.08)$ between the two measures (Provan et al. 1980). Regrettably, this study used measures which did not clearly reflect the common operationalizations of general and issue power, nor were the measures obtained from similar respondent groups. Hence, it remains to be determined whether general and issue-specific perceptual measures reflect different aspects of the concept.

\section{Methods}

\section{Subjects}

The sample consisted of 29 departments in two organizations. This set of departments was exhaustive; thus, all sub-units in both organizations were included in the study. The department was selected as the unit of analysis so as to be consistent with existing research on intraorganizational power and because this unit was 
meaningful and easily identifiable by organizational members.

The two organizations studied, a national fast-food chain of restaurants and a high-technology robotics company, were both structured along functional lines. Departments were organized by function, such as accounting, marketing, human resources, engineering, and manufacturing. These organizations were selected because of their relatively small size (less than 500 employees), diversity of work unit activities, and flat functional organizational designs. Selecting small organizations with flat functional designs allowed for comparability in hierarchical authority of departments relative to each other, while insuring that employees were reasonably familiar with the activities of the various departments. A total of 414 persons in the two companies were surveyed.

\section{Measures}

Perceived departmental power was measured in two ways. First, a general measure was derived from the work of Salancik and Pfeffer (1974). This measure asked respondents to indicate how much influence each department had using a 7point scale ranging from 'no influence' to 'a very great deal of influence'. A 'don't know' response was available and coded as missing data.

The second measure captured the multidimensional aspects of power by taking an issue-specific approach, following the work of Hinings et al. (1974) and Hackman (1985). Respondents were asked to indicate the ability of each department to control specific power issues, using a 7-point scale ranging from 'no ability' to 'greatest ability'. An additional scale item was included allowing respondents to indicate that they did not know whether a department had the ability to affect the specific outcomes. The high level of internal consistency of this measure was evident in the Cronbach alphas of .78 and .77 for the fast-food and robotics firms, respectively.

To arrive at a list of organizationally relevant issues, 81 open-ended interviews were conducted. In both companies, all department heads, a random sample of departmental personnel, and all top managers were interviewed. Table 1 presents the ten issues identified in the interviews; four were unique to each organization, and six were shared in common by both companies. Using the criteria for selection of issues detailed by Hinings et al. (1974), an issue was selected if it was mentioned frequently during the interviews and regarded as a critical area or situation involving more than one department. 
2. Recruiting. Training and Employee Development ${ }^{3}$

3. Problems of Increasing Profitability

4. Quality, Service. Cleanliness and Atmosphere

5. Problems in Monitoring and Controlling Costs ${ }^{b}$

6. Customer Satisfaction

7. When Shipment of the Product will Occur ${ }^{\mathrm{b}}$

8. Development of Policy and Policy Changes ${ }^{b}$

9. Creation of a Unique Culture

10. Long Range Planning (future direction)

11. Increases in Sales

12. Enhancement of a Company Reputation

13. Communication Between Departments

14. Introduction of New Products

a Specific issues in the Fast-Food Company

'Specific issues in the Robotics Company

Note: All other issues are heid in common by both companies

\section{Aggregation}

Individuals were categorized into three respondent groups and their scores were summed and averaged. One respondent group consisted of departmental employees' assessments of their own department's general and issue power. A second group was composed of departmental employees from all other departments. When assessing each department's power this group consisted of all other employees who did not belong to the evaluated department. A third group was made up of top managers who assessed each department on the two power measures. The mean composite score approach to aggregation is similar to that used by Bacharach and Aiken (1976), and has a history of use in the power literature (Perrow 1970; Hinings et al. 1974; Pfeffer and Salancik 1974).

Perrow (1970) suggests assigning equal weights to all respondents because a different decision rule for weighting would be arbitrary. This study adopts Perrow's logic and assigns equal weights to the scores of all respondents. Relying on mean scores for each of the three respondent groups serves to correct for the various sizes of department membership both within and between companies. In addition, reliance on mean scores reduces distortion from individual biases and is a viable approach to reporting macro-level data (Provan 1980).

\section{Results}

Before examining the relationship between the power measures, it is necessary to discern whether individuals within departments are in greater agreement regarding their own department's power than are individuals across departments. One-way analyses of variance were used to test whether the variance of employee responses across departments was significantly greater than the variance within departments. Four separate analyses were run, one for each company on the two measures of power. For the fast-food company, the issue-oriented $(F=2.51, p<.01)$ and general $(\mathrm{F}=3.45, \mathrm{p}<.001)$ measures yielded statistically significant departmental 
differences. In the robotics company, similar results were found for issue-oriented $(F=2.71, p<.01)$ and general $(F=2.92, p<.01)$ power measures. The analyses of variance indicate that within-department variance is significantly smaller than between-department variance. Thus the data provide justification for aggregating department members' perceptions of power.

\section{Convergent Validity of Multiple-Respondent Groups}

The intercorrelations of the power measures using the three respondent groups are presented in Table 2 . The perspectives of the three respondent groups were highly correlated when assessing general and issue-specific power. When assessing power using the same measure, the correlations between respondent groups were significantly greater than zero and large enough to provide evidence for convergent validation. For general power, the Pearson product moment correlations ranged from 0.72 to 0.89 , whereas the comparable correlations for issue-specific power were 0.48 to 0.91 .

Table 2

Intercorrelations Among all the Measures of Power $(n=29)$

\begin{tabular}{|c|c|c|c|c|c|c|c|}
\hline & \multicolumn{3}{|c|}{ Issue-Specific Measures } & \multicolumn{4}{|c|}{ General Measures } \\
\hline & $I_{1}$ & $\mathrm{I}_{2}$ & $\mathrm{I}_{3}$ & $\mathrm{G}_{1}$ & $\mathrm{G}_{2}$ & $G_{1}$ & \\
\hline \multicolumn{8}{|l|}{ Issue-Specific Measures } \\
\hline Own Department $\left(I_{1}\right)$ & & & & & . & & \\
\hline Top Management $\left(\mathrm{I}_{2}\right)$ & $.570 * * *$ & & & & & & ， \\
\hline Other Departments $\left(\mathrm{I}_{3}\right)$ & $.481^{* *}$ & $.912 * * *$ & & & & & \\
\hline \multicolumn{8}{|l|}{ General Measures } \\
\hline Own Department $\left(G_{1}\right)$ & .164 & $.437^{* *}$ & $.469^{\circ}$ & & & & \\
\hline Top Management $\left(G_{2}\right)$ & .253 & $.605^{* * *}$ & $.587 * * *$ & $.737^{* * *}$ & & & \\
\hline Other Departments $\left(\mathrm{G}_{3}\right)$ & .261 & $.711^{* * *}$ & $.734^{* * *}$ & $.717^{* * *}$ & $.892 * * *$ & & \\
\hline
\end{tabular}

a Own - Members of a department's perceptions of their own department's power

Top - Top management's perceptions of departmental power

Other - Members of other departments' perceptions of a department's power

* $p<.05$

* $p<.01$

$\cdots p<.001$ 
These findings suggest that different respondent groups tend to agree on their perceptions of departmental power when examining power using the two measures. Thus, evidence is present to suggest substantial convergent validation by independent groups on the same measures of power.

\section{Discriminant Validity of Power Measures}

The correlations among the three respondent groups on a given measure were greater than the correlations between issue and general power within a respondent group. For example, there was greater agreement between top management's and a department's perceptions of the department's issue power ( $r=$ $.57, p<.001$ ) than between a department's own perceptions of its issue and general power ( $r=.16, p>.05)$. This pattern of relationships held for all respondent groups, but was very pronounced for a department's evaluation of its own power. The pattern of intercorrelations was consistent and the strength of the relationships provided evidence that stronger relationships existed across respondent groups than across measures. It is important to note that for top managers and other departments, the across-measure, within-respondent group correlations were significant, although lower than the within-measure, across-respondent group correlations. Thus the data provide a clear case of discrimination between the general and issue measures when applying the three criteria for discriminant validation presented by Campbell and Fiske (1959).

\section{Hierarchical Regression}

Twelve hierarchical regression models were developed to investigate the incremental variance in one measure of power accounted for by the other measure when taking into consideration the assessments of other respondent groups. If a significant percentage of variance in one measure of power is accounted for by the other measure, it can be concluded that the two measures are capturing a single, overlapping conceptualization of power. On the other hand, if one measure of power does not significantly account for variation in the other, then the two measures do not capture the same underlying components of power.

The regression models are constructed using a specified hierarchy of entry for the independent variables. The specified hierarchy of variable entry requires that different respondents' assessments on the same measure are entered in the equation on the first step. The other measure of power for the focal group (i.e. the group whose perceptions were used as the dependent variable in the equation) is entered on the second step. On the final step, the other measure of power for the other two respondent groups is entered.

Table 3 presents the three regression models in which the dependent variables are measures of issue-specific power. From $57.8 \%$ to $92.8 \%$ of the variation in a respondent group's issue-specific power is accounted for by the two other 
respondent groups on the same measure. When the general measure of power for the focal group is added, only .4\% to $.7 \%$ additional variance in the dependent variable is explained. Thus, general power accounts for almost no variance in issuespecific power, after dividing out the effects of other respondent groups' assessments of issue-based power.

Table 3

Hierarchical

Regression of IssueSpecific Power

\begin{tabular}{|c|c|c|c|}
\hline \multirow[b]{2}{*}{$\begin{array}{l}\text { Regression } \\
\text { Equations }\end{array}$} & \multicolumn{2}{|c|}{ Correlation Coefficients } & \multirow[b]{2}{*}{$\begin{array}{l}\text { Overall } \\
F \text { tests }\end{array}$} \\
\hline & multiple $\mathrm{R}^{2}$ & $\begin{array}{l}\text { change in } \\
\text { multiple } \mathrm{R}^{2}\end{array}$ & \\
\hline \multicolumn{4}{|l|}{ Own Department's Perceptions of its Power } \\
\hline \multicolumn{4}{|l|}{ Step 1: Top Mgt. Issue Power } \\
\hline Other Depts. Issue Power & .578 & .578 & $6.52^{* *}$ \\
\hline Step 2: Dept. Own General Power & .583 & .005 & $4.29^{*}$ \\
\hline \multicolumn{4}{|l|}{ Step 3: Top Mgt. General Power } \\
\hline Other Depts. General Power & .614 & .031 & $2.79^{*}$ \\
\hline \multicolumn{4}{|c|}{$\begin{array}{l}\text { Top Management's Perceptions of a Department's Power } \\
\text { Step 1: Dept. Own Issue Power }\end{array}$} \\
\hline Other Depts. Issue Power & .925 & .928 & $76.54 \cdots$ \\
\hline \multirow{2}{*}{\multicolumn{4}{|c|}{$\begin{array}{l}\text { Step 2: Top Mgt. General Power } \\
\text { Step 3: Dept. Own General Power }\end{array}$}} \\
\hline & & & \\
\hline Other Depts. General Power & .931 & .002 & $29.79 * *$ \\
\hline \multicolumn{4}{|c|}{ Other Departments' Perceptions of a Department's Power } \\
\hline \multicolumn{4}{|c|}{ Step 1: Dept. Own Issue Power } \\
\hline Top Mgt. Issue Power & .914 & .914 & $65.60^{* *}$ \\
\hline \multirow{2}{*}{\multicolumn{4}{|c|}{$\begin{array}{l}\text { Step 2: Other Depts. General Power } \\
\text { Step 3: Dept. Own General Power }\end{array}$}} \\
\hline & & & \\
\hline Top Mgt. General Power & .926 & .005 & $27.75^{\cdots}$ \\
\hline
\end{tabular}

The findings for general measures of power are summarized in Table 4. General power, as perceived by the two other respondent groups, accounts for $74.8 \%$ to $90.3 \%$ of the variance in the focal respondent group's general power. By holding constant the effects of other respondent groups' perceptions of general power, the focal group's issue-specific power accounts for no variance to only $3.6 \%$ of the variance in general power. The low percentage of variance in general power accounted for by issue-based power, and the high percentage of variance in general power explained by different respondent groups assessing general power, indicate that general and issue-based perceptual measures may be capturing very different aspects of power. 
Table 4

Hierarchical

Regression of General

Power

\begin{tabular}{|c|c|c|c|}
\hline \multirow[b]{2}{*}{$\begin{array}{l}\text { Regression } \\
\text { Equations }\end{array}$} & \multicolumn{2}{|c|}{ Correlation Coefficients } & \multirow[b]{2}{*}{$\begin{array}{l}\text { Overall } \\
F \text { tests }\end{array}$} \\
\hline & multiple $\mathrm{R}^{2}$ & $\begin{array}{l}\text { change in } \\
\text { multiple } \mathrm{R}^{2}\end{array}$ & \\
\hline \multicolumn{4}{|c|}{$\begin{array}{l}\text { Own Department's Perceptions of its Power } \\
\text { Step 1: Top Mgt. General Power }\end{array}$} \\
\hline Other Depts. General Power & .748 & .748 & $16.55^{* * *}$ \\
\hline Step 2: Dept. Own Issue Power & .749 & .001 & $10.66^{* * *}$ \\
\hline \multicolumn{4}{|l|}{ Step 3: Top Mgt. Issue Power } \\
\hline Other Depts. Issue Power & .755 & .006 & $6.11 \cdots$ \\
\hline \multicolumn{4}{|c|}{$\begin{array}{l}\text { Top Management's General Perceptions of a Department's Power } \\
\text { Step 1: Dept. Own General Power }\end{array}$} \\
\hline Other Depts. General Power & .903 & .903 & $57.46^{* \cdots}$ \\
\hline Step 2: Top Mgt. Issue Power & .903 & .000 & $36.95 * \cdots$ \\
\hline \multicolumn{4}{|l|}{ Step 3: Dept. Own Issue Power } \\
\hline Other Depts. Issue Power & .911 & .008 & $22.57^{\cdots} \cdots$ \\
\hline \multicolumn{4}{|c|}{$\begin{array}{l}\text { Other Departments' General Perceptions of a Department's Power } \\
\text { Step 1: Dept. Own General Power }\end{array}$} \\
\hline Top Mgt. General Power & .896 & .896 & $53.18^{\cdots}$ \\
\hline Step 2: Other Depts. Issue Power & .932 & .036 & $54.91^{*} \cdot$ \\
\hline \multicolumn{4}{|l|}{ Step 3: Dept. Own Issue Power } \\
\hline Top Mgt. Issue Power & .935 & .003 & $32.11 * \cdots$ \\
\hline
\end{tabular}

$\cdot p<.05$

$\cdots p<.01$

$\cdots p<001$

\section{Cross-Validation Analyses}

Six additional hierarchical regression analyses were conducted to ensure that the findings were not due to multicollinearity. Following the suggestion of Cohen and Cohen (1975), the hierarchical order of entry of variables was altered such that the focal respondent group's assessments of power on the other perceptual measure was entered on the first step, followed by the other respondent group's assessments on the same perceptual measure.

These analyses revealed that the variance in issue-specific power accounted for by the general measure of power ranged from $1 \%$ for a department's own evaluation to $54 \%$ for other departments' evaluations. Using the general measure as the dependent variable and entering the issue measure of the focal group on the first step revealed that a department's and top management's assessments of power were divergent between measures and convergent between respondents. Other departments' assessments of a department's general and issue-specific power were not clearly distinctive.

\section{Discussion}

The findings strongly suggest that the general and issue-specific perceptual measures used in this study are capturing different aspects of power in organizations. The degree of consensus between differing respondent groups when evaluating departmental power on the same measure further strengthens the argument that 
general and issue-specific perceptual measures of power may not capture the same components of power.

One possible explanation for the divergence between the two measures of power is that they measure enacted and potential power in differing degrees. While it has been argued that both potential and enacted power are incorporated into perceptual measures of power (Provan et al. 1980; Beyer 1982), the findings reported here raise the possibility that perceptual measures may vary in the degree to which they capture components of potential versus enacted power.

Since the issue-based measure of power asks respondents to assess a department's capacity to influence, it may be tapping the future potential of a subunit to influence. In contrast, a general measure of power directs the respondent to examine how much influence the sub-unit has had, thus directing attention to past actions or power that have been exercised or enacted. While this explanation is speculative, the present study does indicate that, depending on the measure selected, very different findings may result.

The degree of divergence was most dramatically demonstrated for the members of departments who assessed their own department's issue and general power. In this case, knowledge of enacted and potential power may be more easily distinguished. It is also possible for a sub-unit to inflate its general power because of the absence of a reference point, while providing a more reasoned appraisal of its potential issue-specific power. As the group evaluating a department's power is further removed from the department (i.e., top management and other departments), responses on general and issue- specific measures may become less distinguishable. Finally, top management may have the clearest understanding of enacted and potential power because they are not hampered by the overestimates of influence likely to plague a self-reporting sub-unit or the lack of knowledge likely to cloud the assessments of other sub-units.

This investigation provided evidence of divergent validity between two popular perceptual measures of departmental power. The general and issue-specific perceptual measures appear to be capturing different aspects of power; hence, caution should be exercised in the selection of one measure over another. A general measure may capture enacted power while an issue-based measure may reflect the future potential to influence.

The introduction of a multiple respondent approach strengthened the analysis, particularly since top managers' discriminations between the two measures corresponded with the distinctions drawn by the potentially biased departmental members. Future research on intraorganizational power would be improved by considering multiple perceptual measures and the use of a multiple respondent approach. Our understanding of perceptual measures would be enhanced if future researchers carefully devised their measures to capture potential and enacted power, 
and then compared their findings with those obtained from objective measures of potential and enacted power. In sum, researchers are advised to examine the possible conceptual as well as methodological distinctions between general and issue-specific measures before selecting a perceptual measure of departmental power.

\section{References}

Bacharach, Samuel B , and Michael Aiken

1976 'Structural and process constraints on influence in organizations: A level specific analysis'. Administrative Science Quarterly 21: 623-642.

Beyer, Janice M.

1982 'Power dependencies and the distribution of influence in universities' in Research in the sociology of organizations, Vol. 1. S. B. Bacharach (ed). 167208. Greenwich, Conn: JAI Press.

Campbell, D. T., and D W. Fiske

1959 'Convergent and discriminant validation by the multitrait-multimethod matrix'. Psychological Bulletin 57: 260-261.

Cohen, Jacob, and Patricia Cohen

1975 Applied multiple regression/correla- tion analysis for the behavioral sciences. New York: John Wiley.

Hackman, Judith Dozier

1985 'Power and centrality in the allocation of resources in colleges and universities'. Administrative Science Quarterly 30: 61-77.'

Hinings, C. R., David J. Hickson, Johannes M. Pennings, and R E. Schneck

1974 Structural conditions of intraorganizational power' Administrative Science Quarterly 19 : 22-44.

Pennings, Johannes

1973 'Measures of organizational structure: A methodological note'. American Journal of Sociology 79: 686-704. 
Perrow, Charles

1970 Departmental power and perspectives in industrial firms' in Power in organizations. M. N Zald (ed.), SOSO. Nashville: Vanderbilt University Press.

Pfeffer, Jeffrey, and Gerald R. Salancik

1974 'Organizational decision making as a political process: The case of a university budget' Administrative Science Quarterly 19: 135-151.

Provan. Keith G.

1980 Recognizing, measuring, and interpreting the potential/enacted power distinction in organizational research'. Academy of Management Review 5: 549-560*

Provan, Keith G., Janice M. Beyer, and Carlos Kruytbosch 1980 'Environmental linkages and power in resource dependence relations between organizations'. Administrative Science Quarterly 25: 200-225.

Salancik, Gerald R., and Jeffrey Pfeffer

1974 The bases and uses of power in organizational decision making: The case of a university'. Administrative Science Quarterly 19: 453-173.

Sathe, Vijay

1978 Institutional versus questionnaire measures of organizational structure' Academy of Management Journal 21: 227-238.

Wrong, Dennis H.

1978 Power: its forms, bases, and uses New York: Harper and Row. 